\title{
RACIALIZED ELDERS: ISSUES AND APPROACHES FOR SERVING CANADA'S IMMIGRANT ELDERS
}

By

Arafat Mustafa, BSW, Ryerson University, 2019

\author{
An MRP \\ presented to Ryerson University \\ in partial fulfillment of the \\ requirements for the degree of \\ Master of Social Work \\ in the Program of \\ Social Work
}

Toronto, Ontario, Canada, 2019

(C) Arafat Mustafa 2019 


\section{AUTHOR'S DECLARATION FOR ELECTRONIC SUBMISSION OF AN MRP}

I hereby declare that I am the sole author of this MRP. This is a true copy of the MRP, including any required final revisions.

I authorize Ryerson University to lend this MRP to other institutions or individuals for the purpose of scholarly research

I further authorize Ryerson University to reproduce this MRP by photocopying or by other means, in total or in part, at the request of other institutions or individuals for the purpose of scholarly research.

I understand that my MRP may be made electronically available to the public. 


\section{ABSTRACT \\ RACIALIZED ELDERS: ISSUES AND APPROACHES FOR SERVING CANADA'S \\ IMMIGRANT ELDERS}

Master of Social Work, 2019

Arafat Mustafa

Program of Social Work,

\section{Ryerson University}

Using a narrative approach to qualitative research, this study involved interviewing three East African seniors about their perceptions of long term care facilities. The participants shared their insights into long term care facilities, the lack of services and systemic barriers that they face as racialized elders in Canada.

Key words: racialized minorities, elders, seniors, long term care, systemic barriers 


\section{ACKNOWLEDGEMENTS}

I would like to thank my MRP supervisor Gordon Pon for the enormous continual support and encouragement while conducting this study. Thanks, Gordon, for being such a wonderful person. His support from the beginning of my research to the end is something that I would not forget.

I am very grateful to Dr. Purnima George who has been with me through my tough time when I started this master's program. When I doubt myself, she encourages me to go through with my dreams. I thank May Friedman for being such a wonderful inspiration to me.

I would like to thank my Mom and Dad for their blessings and the unconditional love that gives me strength.

A special acknowledgement to my colleagues who were there for me in every step of this journey. I could not have done this program without their help and continued support. 


\section{DEDICATION}

I would like to dedicate this research project to my children:

$$
\begin{aligned}
& \text { My Daughter Iffat Abdallah } \\
& \text { My Son Yusry Abdallah } \\
& \text { My Son Fihry Abdallah }
\end{aligned}
$$

Dearest, Iffat, Yusry and Fihry,

Words cannot express how I am deeply excited and honoured to have you as my family. You have always inspired me to achieve more in life. Thank you for your continued support in this long journey. I am so blessed to have you in my life. 


\section{TABLE OF CONTENTS}

Chapter 1: Introduction

Page 1

Chapter 2: Literature Review

Page 5

Chapter 3: Theoretical Frameworks

Page 14

Chapter 4: Methodology

Page 22

Chapter 5: Findings

Page 32

Chapter 6: Discussion and Analysis

Page 38

Chapter 7: Conclusion

Page 41

Appendices

Page 47

Reference List

Page 63 


\section{LIST OF APPENDICES}

Appendix A - Consent Form ................................................................................. 42

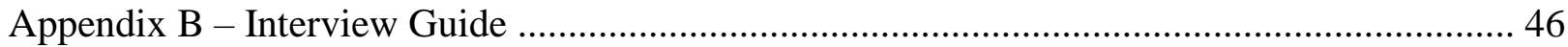




\section{CHAPTER 1: INTRODUCTION}

This study was conducted to explore the counter narratives of racialized elders, specifically from East Africa, and their experiences and perceptions of healthcare services for racialized minorities. The goal of the study is to challenge the assumptions, discourses, and stereotypes that have been negatively affecting racialized minority elders in Canada. As the baby boom generation of Canada enters its senior years, the aging population is expected to increase by $23 \%$ by the year 2036 (Statistics Canada, 2009), which is double the number 25 years ago. This will present a large burden to the government because of the increase in demand for health care, social services, public pensions and housing for our nation's elders, specifically for those from immigrant populations.

By the time this generation shifts to an aging population there will be a significant number of retired members who will no longer be able to contribute to Canada's workforce due to certain factors such as ill health, injury, disability, and elderly abuse (Rockwood et al., 2011). These trends

flag the urgent need for policies to be implemented in areas such as health, long term care and social well-being that reflect Canada's cultural diversity. In today's modern world a person can expect to live up to the age of eighty-five with good health due to improvements in nutrition, access to medical care and a healthy environment. But the elderly are still prone to illness and injury (National Institute of Health, 2011; Rockwood et al., 2011). It has been found that the prevalence of frailty increased exponentially with age throughout the adult lifespan and absolute mortality in relation to frailty was higher with increasing age (Rockwood et al., 2011). In 2015, there were more Canadians over age of 65 than there were Canadians under the age of 14 (Statistic Canada, 2015). This population is diverse in terms of its cultural and racial background, sexual orientation, ability, gender, identity and religious affiliation, among other aspects of identity. In 2006, 30\% of Canadians 65 years and over were from an immigrant background, with $10.3 \%$ of that population 
being racialized minorities (Ng, Lai, \& Rudner, 2012). In the future, Canada's older adults will be even more diverse.

I live in a community with a diverse population, including new immigrants and refugees who experience harsh racism, oppression and political instability in their countries of origin. I have observed the need for a change in the framework of practice. For more than ten years I worked and volunteered directly with the elderly and observed firsthand the issues in the system. I listened to the voices of many concerned Canadians from various ethnic backgrounds. This Major Research Paper (MRP) bridges my earlier professional and academic background as a policy maker with my lived experience in Toronto's newcomer community and work experience with racialized elders. As an anti-oppressive social work student, I deliberately chose to use this research project to contribute to a reframing of the way we see older generations and afford them the due respect and care for their service to Canadian society. I realize that there is a huge lack of services for underprivileged populations, specifically seniors, who are often left feeling incapable and discouraged as a result of internalizing discriminatory judgements. I have become aware of essentialization, which has ignited within me a passion to work with the aging population. It will allow me to reflect on my own experiences as a middle aged, immigrant woman of colour, as well as allow me the opportunity to create a space which privileges the voices of racialized minorities.

Many older adults face an intersection of multiple forms of oppression based on their sex, gender and race, among other aspects of social differences. Young (1990) stated that "In the most general sense, all oppressed people suffer some inhibition of their ability to develop and exercise their capacities and express their need, thoughts, and feelings. In that abstract sense all oppressed people face a common condition" (Young, 1990, p. 40). Historically, older adults have been characterized in the past as wise and history knowers in many societies, but things have changed; 
now we often perceive them to be an economic burden. Older adults may be viewed as valuable assets in times of economic expansion, but readily disposable and a burden during recession periods. Ageism is a social construction; it is more than an attitude; it is a systemic, cultural, and structural form of oppression where certain groups are treated differently in comparison to others due to age.

My research focuses on issues experienced by three participants of the aging population, especially those from immigrant communities of East African origin. This is a community where I have greater access to and acceptance in because of my Swahili language skills and my past service. My research is guided by an anti-oppressive approach. A critical component in social work is the deconstruction of oppressive discourse and knowledge (Massaquoi, 2011; Mullaly, 2010). This approach will allow me to explore structural inequality, systemic barriers and the social construction of aging and the implications for social work practice. The use of a critical antioppressive approach will guide the theme of client empowerment as it will focus on responding to the needs of a client regardless of their social status. This research will be done by employing a qualitative research methodology. I will advocate for the immigrant elderly population within the framework of the Social Work Code of Ethics. This will allow a space to not only examine the relevance of 'voice' of the elderly population, but also educate the public and build awareness of prevalent stereotypes towards the aging population in Canada.

There is a lack of studies on elders from visible minority backgrounds; additionally, the model of long-term care facilities and service provision in Canada is based mainly on western culture. Eurocentrism dominates health services, which in turn, fails to account for the culturally specific needs of clients and often create barriers for them to access appropriate treatment (Sakamoto, 2007). This often creates conflict and uncertainty between service users and service 
providers because of different values and beliefs, as well as an overload of work. An antioppressive approach addresses the prejudices and inequitable relations that communities experience and works to seek fundamental change in the structures that perpetuate oppression (Parada, Barnoff, Moffat \& Coleman, 2011). In this context, this MRP captures the experiences and perceptions of racialized minority elders and seeks to amplify their voices. As an antioppressive researcher, I must examine ageism discourses and the aging process, connecting issues with social structure, dominant discourses and unequal power distribution. I believe that this study is important to social work because it impacts social workers in diverse fields, and it will provide them with an understanding of the experiences of three racialized elders. This study is meant to help social workers, as well as other service providers, to work together with racialized minority elders in order to maintain the well-being of the elderly in long-term care facilities. 


\section{CHAPTER TWO: LITERATURE REVIEW}

The literature reviewed for this MRP demonstrates how the concepts of racism, marginalization, and the unequal distribution of power are ultimately linked to the issues experienced by racialized aging populations. The literature reviewed on the aging population and long-time care within diverse communities emphasizes a western model of care for the elderly. Gele and Hasloff (2012) conducted a qualitative study of 24 African immigrants who were 50 years and older and used semi-structured interviews to explore the barriers they experienced in civic engagement. These issues included language barriers, mistrust of organizations and a lack of information about relevant organizations, which are crucial factors for their well-being. Poor health conditions were among the findings of the study, and there was a call to action for service providers and policy makers to address these barriers (Gele \& Haslof, 2012). Sethi and colleagues (2018) explored the experience of Chinese immigrant caregivers by interviewing thirteen different individuals. The findings revealed that family conflicts were the result of cultural differences as well as intergenerational gaps between the caregivers, employees and their care recipients (Sethi et al., 2018). The available literature also included discussions of senior's health and the issues regarding the decision of placing an elderly person into a long-term care facility. The literature revealed a gap regarding a misunderstanding of the roles of caregivers and service providers, especially in health-care facilities. This gap is due to role conflicts, role ambiguity and work overload that contribute to abusive behavior towards elderly people (Altman \& Cohen, 2009).

Many elders from immigrant communities have different views of growing old compared to their Canadian-born counterparts. The theme of discrimination was found in a study done by Stewart and colleagues (2011), which analyzed diverse ethnicities including Chinese, Caribbean, African, Yugoslavian and Spanish. The participants of various ethnicities were interviewed and 
asked about the barriers that elderly people in their community face in regard to accessing services in Canada (Stewart et al., 2011). The findings from the interviews included language barriers, lack of appropriate services, health problems, discrimination, family conflicts and isolation, which negatively impacted elderly immigrants in terms of accessing different services in Canada (Stewart et al., 2011).

In their research regarding linguistic diversity in long-term care, Small and colleagues (2005) recorded 27 staff members and 27 residents who consented to being video-recorded doing routine activities (i.e. meal time and recreational activities). They were interested in studying what would happen when the staff and resident did not speak the same language. It appeared that the resident's quality of communication and care was jeopardized. The findings provide points to consider in order to effectively accommodate language and ethnocultural diversity in long-term care practice. In her article, Dossa (1999) emphasized the theme of voice by using an ethnographic research approach. The expressed goal of the research was to give space for the voices of research participants, which can further enhance the anthropological endeavor of intercultural dialogue (Dossa, 1999). According to Dossa (1999), the life story approach can expand the scope of ethnography through explicit recognition of the ongoing dialogue between narrators and the ethnographers. Dossa (1999) stated that "critical anthropology can strengthen the discipline's conventional roots in the imperialist complex of West versus the rest [third world]" (p. 335). By using a qualitative descriptive approach, Miner and colleagues (2018) explained the health care services that are needed for Somali ethnic elders, while also explaining the experiences of home health care, which may be preferred by Somali ethnic elders when compared to long term care facilities. The findings indicated the importance of agencies and organizations working together 
collaboratively with communities in order to facilitate a better understanding of health care (Miner et al., 2018).

The literature review also highlights the prevalence of structural violence in long-term care facilities for older adults. Benerjee and colleagues (2012) conducted a study by comparing frontline workers between Canada and Scandinavia and found that Canadian frontline workers are almost six times as likely to report that they experience physical violence from residents or family members (Benerjee et al., 2012). The 2007 study utilized focus groups and revealed that violence was often normalized as an inevitable part of elder-care (Benerjee et al., 2012). Hence it shows how systemic and organizational factors play out in establishing a context for violence. The notion of violence allows us to look at the systemic way that institutions and structures serve to prevent these frontline workers from reaching their full potential or achieving their dreams of success (Benerjee et al., 2012).

In their study, Altman and Cohen (2009) spoke about seniors' health and other issues associated with the decision of placing an elderly person in a long-term care facility. The authors mentioned a misunderstanding pertaining to the roles of caregivers and service providers, particularly in health care facilities. It is this role conflict, role ambiguity and work overload that contributes to abusive behaviours towards elderly people (Altman \& Cohen, 2009). Walsh et al. (2011) studied how poverty, race, age, disability, gender and sexuality affected the occurrence of elder abuse. In their study, they analyzed data from focus groups with older adults and caregivers. The article includes information on the intersection of elder abuse, ageism and other forms of oppression. They also highlighted the marginalization of Indigenous peoples and racial groups as a factor that caused elder abuse. Many service providers focused on culture and acculturation and pay less attention to the intersection of racism, cultural practices and other forms of inequality and 
oppression (Walsh et al., 2011). The link between elder abuse, ageism and other forms of oppression emerged as a significant research gap for elders.

Many immigrant elders wish to age in place in their homes surrounded by their family members and friends. Due to various circumstances, many elders are being placed into long-term care facilities. The article by Miner and colleagues (2018) explores the perception of adult home care services by older adults from the Somali communities. In this paper, a qualitative descriptive approach was used to explain the health care services that are needed for Somali elders and their experiences of home health care, which is preferred by many as opposed to living in facilities. The findings of the study include the importance of agencies and organizations working with communities in order to facilitate a better understanding of appropriate health care practices.

In their study, Kaplan and colleagues (2015) sought to understand the perceptions of Ghanaian immigrants regarding their health status and the health trajectory of their community. They found that Ghanaians are generally healthy when they arrive in the US, but that their health declines over time. Participants identified four causes of this perceived deterioration: changes in health behaviors, increased stress, environmental exposures, and barriers to health care (Kaplan et al., 2015). Participants see themselves as being at risk for many health problems resulting from the changes in lifestyle that follow immigration. Many of the risk factors that participants described are the same as those that affect other residents in the communities in which they live (Kaplan et al., 2015).

In their article, George and George (2013) explained the role of neoliberal social policy that has shifted the responsibility for the welfare of people from the government and the state, to that of the family and the individual. They stated how the notion of being an ideal citizen is not working within the current reality, and that class, race, gender and age create barriers that prevent 
people from accessing resources (George \& George, 2013). This again shows how policies have participated in the discrimination against racialized groups, including their elders. The neoliberal government ideology that ranks deservedness based on economic and financial contribution to society is punishing seniors who may have contributed to their families or communities in other ways (George \& George., 2013). The dependency of adults on their children is in part because of the unavailability of old age security, which has also contributed to intergenerational conflict (George \& George., 2013; Matsuoko et al., 2013). To be sure, there is a need to introduce appropriate aging policies to meet social and economic change (Matsuoko et al., 2013).

Critical qualitative inquiry was implemented in most of the available research I reviewed, which supports the argument by Denzin (2017) that there is a need to imagine and engage with innovative ways of doing critical qualitative inquiry especially given our current neoliberal times (2017). The strengths of using anti-oppressive and critical race theory in research regarding aging and long-term care include its exploration of structural inequality, systemic barriers and the social construction of aging, and the associated implications for social work practice.

The limitation of the available literature is that there is an enormous gap regarding research around the ageing of elders from visible minorities, especially from East-African origin or other parts of Africa. The model of long-term care facilities in Canada is based on western cultural norms. The discrepancy in values and beliefs often results in conflict and uncertainty between service users and service providers. According to Charmaz (2017), critical theory includes concerns and studies about social justice; she stated that "critical inquiry is embedded in a transformative paradigm that seeks to explore, oppose and redress forms of oppression, inequality and injustice" (p. 35). As mentioned by Sekudu and Mathebane (2000), coloniality and modernity are two-sides of the same coin, locating Europe and modern sciences at the epicentre of knowledge 
production and as experts of things outside of their own society. However, many of these researchers lack knowledge of how people from minority groups and diverse backgrounds perceive aging and that, for most people, especially those from the sub-Saharan part of Africa, having to live in a facility means living a life of isolation.

It becomes an enormous burden on families when they reach the point where they believe they have no other option but to place their family member in a care facility. To ease this burden, family members require a place that is going to have culturally oriented services. The available literature discussed broad issues concerning seniors and their families using various perspectives such as ageism; elder abuse; senior gambling; loneliness, and depression among adults. However, issues associated with older adults in long-term care facilities was rarely mentioned in articles written in the past 10-15 years. Due to the lack of available research on this topic and the growing 'baby boomer' population in Canada, I am interested in further exploring this topic area. More issues facing seniors and their families are expected, and therefore, there is a need to promote innovative approaches to address the issues related to older adults.

Love, romance and sexual relationships later in life have been neglected, and even gerontology researchers avoid discussing these topics because they are often seen as taboo areas. This attitude towards older adults manifests in subtle and varied ways. Bauer and colleagues (2007) stated that romantic love and healthy sexual relationships are a powerful force in human development. These relationships play an important part later on in life because love makes individuals healthier, it boosts the immune system, stimulates the activity of neuron cells, and promotes pleasure and positive attitudes in old elders (Bauer et al., 2007). Ward and colleagues (2005) indicated that sharing a kiss, holding hands, bonding with a loved one, having loving hugs 
or writing love letters are not only important for younger people. Experiencing love can reduce stress, increase life longevity and enhance the quality of life (Hullet, 2004).

The disciplines that have contributed to the knowledge on this topic include numerous journals from psychology, gerontology, cross-cultural gerontology, community studies, migration, health studies and social work. In one article by Dossa (1994), the researcher used critical autoethnography to conduct her research. By using critical autoethnography, the dispersal of authority comes at a time when the Other's voice needs to be acknowledged and heard (Dossa, 1994). The available literature on senior mental health was limited and the research that did exist minimally discussed mental illness among elders within immigrant populations. One article emphasized that mental health services need to be flexible to meet the needs of an aging population by providing comprehensive services and focusing on specific ethnic groups (Guruge et al., 2015). In their research on health and health care access experienced by ethnocultural minority older adults, Kohen and colleagues (2012) focused on Canada and other countries with similar populations of immigrants and similar health care systems. They explored different factors, including culture and ethnicity, by looking at the experiences of adults who faced inequities within the context of systemic oppression (Koehn et al., 2012). The researchers found that although Chinese and South Asian communities have the most representation in the available literature, even for these groups many topics remain unexplored, particularly in regard to health and health care systems (Koehn et al., 2012).

Bill C-36, Protecting Canada's Seniors Act, was recently introduced in Canada. The bill intends to amend the criminal code to add age and other "personal circumstances," such as health and one's financial situation, as "aggravating" factors that may prompt a judge to impose a harsher sentence on an individual convicted of a crime against an elderly person (Post Media News, 2012). 
There are many areas of law that impact older adults, including family relations, marriages, property rights, assault protection, health consent, human rights and employment (Spenser \& Soden, 2007). Although there have been private members' bills put forward from time to time, there is no specific criminal charge of "elder abuse" in Canada (Spenser \& Soden, 2007). It is estimated that $7 \%$ of adult Canadian seniors have experienced some type of abuse in their home or private place of residence (Spenser \& Soden, 2007). The federal government amended Bill C36 that sought to impose harsher sentences on the abuser. Regulations are measures taken by government units to influence people by means of formulated rules which must be obeyed by the controlled person or group (Vedung, 1998, p.720). Regulations are the traditional instrument of government. The primary law in this case would be the laws and regulations within the Canadian Criminal Code that have been set out for members of society to abide by. The main policy tools that are used to address elder abuse problems are described as "sticks," because they are coercive and aggressive in nature. The government uses these sticks to force the recalcitrant to obey the rules and harsh punishment will be given if the rules are not followed. Bill C-36 is also an authoritative tool that has been used to amend the criminal code. The people that are targeted by this policy are both elders and abusers. The elders are seen as dependent, deviant and unproductive based on their socioeconomic location, and the abusers are seen as irresponsible and a danger to our society, and therefore, deserve harsh punishments. Elder abuse is based on the social construction of ageism. Ageism is prejudice against older adults and refers to the way older adults are discriminated against, marginalized, devalued and impeded from feeling good about themselves and their contributions to the societies in which they live. (Spenser \& Soden, 2007; Tam \& Neysmith,.2006, Tyyskä et al., 2012). Canadian researchers examining elder abuse in 
racialized immigrant populations have identified the interlocking factors of social exclusion, structural racism and a lack of respect for elders as caused of elder abuse (Tyyskä et al., 2012).

One of the limitations of the available social work literature is that there is not much research focusing on specific services needed for an aging population from diverse immigrant communities. This type of research is increasingly important as baby boomers continue to age and will require a range of services. Other disciplines addressed the racism, discrimination and negative attention that seniors experience from their respective service provider. Katz and Calasanti (2015) addressed the intersections between race, ethnicity, gender, and age. They stated that racial ethnic minority group members did not receive equivalent treatment for dementia despite their receipt of Medicare, even when socioeconomic status, health care access and utilization, and comorbidities are considered. (Katz \& Calasanti, 2015) This is a significant challenge for many seniors from diverse minority backgrounds. Seniors described institutional discrimination as a major barrier in accessing support services and programs (Stewart et al., 2011). They encountered systemic barriers such as government policies, culturally inappropriate programs as well as language problems as well as inadequate financial and human resources which leads to inappropriate programs for these elders (Stewart et al., 2011). They emphasized that it was essential for the service provider to have a thorough understanding of how to work with elders in minority groups. By using different ways of knowing, space will be created to examine the relevance of 'voice' of elderly populations, the conditions under which people live and learn, and shape both their knowledge and their worldviews (Billings, 2000). My research project aims to provide some insights into the experiences of three East African seniors and their thoughts about aging in Canada. 


\section{CHAPTER 3: THEORETICAL FRAMEWORK}

This MRP uses an anti-oppressive framework (AOP) which emerged in Canada in 1990s. It is an umbrella term that refers to an approach that aims to eliminate all oppressions. An AOP framework suggests that human experiences are shaped by a variety of social differences (Pon et al., 2016). A critical component of anti-oppressive social work is the deconstruction of oppressive discourses and knowledges (Massaquoi, 2011). According to Baines (2011), AOP is a social justice-oriented practice that examines power dynamics which work to marginalize people, while identifying strategies to empower them across a wide range of social settings, relations, environments and systems. Using an AOP perspective, this paper examines and focuses on the experiences of racialized seniors and aging racialized minorities. Eurocentrism dominates health services, which fails to account for the culturally specific needs of clients and often creates barriers in accessing appropriate treatment. The aim of AOP is to address the power imbalances between social workers and service users, and to eradicate oppressive structures and unequal power relationships (Pon et al., 2016). AOP encourages the adoption of multidimensional analysis that recognizes the personal, cultural and structural dimensions of the oppressions experienced by marginalized populations (Hailey, 2014). Through research analysis, AOP social work scholars aim to disrupt commonplace knowledge that is harmful or exclusionary to oppressed peoples (Massaquoi, 2011).

I have chosen to use this framework because anti-oppressive research is committed to a particular purpose, and it encourages researchers and the communities they work with to actively participate in seeking social change to ensure the inclusion of all marginalized and oppressed social groups. Anti-oppressive practice focuses on the analysis of structural oppressions and power relations underlying the issues faced by service users and user systems (Sakamoto, 2007). 
Qualitative AOP research proposes that knowledge should come from those who experience the reality and not those who have political or social control (Creswell, 2013; Potts \& Brown, 2005). AOP research allows researchers and researched social groups to have an equitable and mutual relationship, in which the voices of marginalized groups can be heard (Brown \& Strega, 2005). I wanted to conduct this research to support and advocate for the importance of culturally appropriate services for elders and to identify structural barriers that elders from racialized minorities face, especially pertaining to long-term care facilities. An AOP perspective helped to highlight the reality of racialized seniors and challenge the unbalanced power dynamics. AOP is based on a recognition of the structural origins of services users' problems and seeks to transform power relations in practice (Hailey, 2014). Power as a dynamic argues that people are oppressed based on their identities and positions (Pon et al., 2016). In this context, this paper aims to capture the experience of racialized minority elders and to amplify their voices. Positivist epistemologies place the researcher in a position of power and as the creator of knowledge. In contrast, an AOP approach seeks to dismantle that paradigm and shift the focus to creating and co-constructing knowledge with those who are marginalized. By using this approach, I hope to support and advocate for racialized seniors impacted by systemic barriers and structural inequality. 


\section{CHAPTER 4: METHODOLOGY}

In this section I will describe narrative inquiry and explain why I believe it is suitable for my research. This section will also include a description of how participants were recruited, the data collection tool I used and how the data was analyzed.

\section{Research Design}

My research used a narrative approach. According to Creswell (2013), the narrative approach is a qualitative approach to research that is both a product and a method. Narrative is also a study of stories or descriptions of people's experiences. Narrative inquiry is an interdisciplinary study of the activities involved in generating and analyzing stories of life experiences, a series of events (such as life histories, narrative interviews, journals, memoirs, autobiographies, diaries, biographies) and then reporting on the results (Schwandt, 2007, p. 204). I used the narrative approach because it aims to give voice to those whose stories have been previously unheard in scholarly research (Chase, 2005; Creswell, 2008). I believe it was an appropriate choice for my research as it focuses on the experiences of a few participants, rather than those of a larger group. With this research, I as a researcher and my research participants had a conversation or discussion regarding their perception of various issues experienced by elders within racialized communities.

Narrative approach can facilitate advocacy for marginalized people and to ensure that these voices are heard. It is also a good way for the researcher to gain insight into his or her own life because it situates individual stories within participant's personal experiences, their culture and their historical context (Creswell, 2007). In my narrative research, the research participants and I discussed their perceptions of long-term care facilities. By using this approach, I strongly believe 
that it deepened my understanding and also gave the participants the courage to make their voices heard.

Active collaboration with the participant is necessary when doing this type of research. According to Creswell (2008), the researcher needs to discuss the participant's stories, as well as be reflective about their own personal and political background, as these shape how they "re-story" the narratives. I chose interview questions that allowed the participant to describe and tell their stories, as these are the experiences and perspectives I was interested to hear (Chase, 2003). My research participants are underprivileged seniors from racialized communities. They were given the opportunity to narrate their own stories and speak about their needs by having the chance to reflect on how a lack of necessary social services has impacted their emotional and physical wellbeing. Narrative approach is an effective methodology that allows people to make sense of their experience, construct the self, and create and communicate meanings (Chase,2003). This will bring awareness to this particular topic and increase knowledge production on this topic area. In using a narrative approach and actively collaborating with my participants, I was able to collect extensive information about participant's personal experiences, their culture and their historical context. Throughout this research, I was guided by an anti-oppressive theoretical lens that advocates for these marginalized voices to be heard.

\section{Research Participants}

To be included in this study participants had to be adults aged 65 years and older who anticipated being in need of a long-term care services in the future. All the participants had to selfidentify as racialized and as an immigrant from East Africa. I purposefully chose to only include adults who are not currently living in long-term care facilities because the baby boomer generation in Canada is entering its senior years and will increasingly require access to long-term care 
facilities. This will present a large burden to the government because of the increasing demands on health care, social services, public pension and housing for seniors. My rationale for selecting elders from East African backgrounds was to get a more comprehensive understanding of their lives experienced, as this group is largely excluded from the available literature. My goal was to explore the perspectives of racialized minorities of East African origin regarding their thoughts on long-term care facilities and services.

\section{Recruitment}

While recruiting, potential participants were contacted based on whether they met eligibility criteria for this study using the snowball method. I reached out to my friends, peers and community members by email and asked them to pass along my research invitation to other people in their networks that I did not have a direct relationship with. I also asked my contacts to circulate my recruitment letters where applicable. Additionally, members of my cohort in the Master of Social Work program at Ryerson University offered to share my recruitment letter with their contacts. Interested participants were provided with both my email address and phone number and were able to contact me by their preferred method. I discussed the objective of the study and potential risks of the study with participants. Greenhalgh and colleagues (2005) stated that the validity of the research process rests heavily on evidence of the researcher's reflexive awareness. I am aware of my position as a researcher and made every effort to engage in dialogue with my participants as equals. Measures were taken to ensure that participant's thoughts, feelings and opinions were expressed. Participants were asked to share initial consent and contact information with me and were given the opportunity to then ask any further questions they had. Participants were then asked to provide formal written consent upon agreement to participate in an interview (please see appendix A for a copy of this consent form). 


\section{Data Collection}

Individual interviews were utilized as the data collection method in this study. In comparison with other research methods, interviews are powerful in eliciting narrative data that allows researchers to investigate people's views in greater depth (Alshenqeeti, 2014). As mentioned by Cohen and colleagues (2007), interviewing is a valuable method for exploring "the construction and negotiation of meanings in natural setting" (p. 29). The one-on-one interviews were semi structured and were driven by a series of questions set out in advance to allow depth to be achieved by providing the opportunity on the part of interviewer to probe and expand the interviewee's response (Alshenqeeti, 2017). Semi-structured interviews also allow for dialogue creation which led to the emergence of a variety of other questions (Alshenqeeti, 2017). These interviews also enable interviewees to "speak in their own voice and express their own thoughts and feelings" (Berg, 2007, p. 96). The researcher must recognize the key role they play in constructing the data presented, which in this case is the participants' stories, and should ensure these stories are not misrepresented (Riessman, 2008). Semi-structured interviews were conducted, which have proven to be a successful data collection method in other studies with immigrants (Gele, 2012). I conducted interviews with a pre-planned interview guide and used additional questions that occurred in response to participant's answers (See appendix B for a copy of the Interview Guide).

In this study, three interviews were conducted with elderly immigrants, and each interview ranged from 60 to 90 minutes. All the interviews were audio recorded with participant's consent and were transcribed and analyzed. Each interview took place at a different location based on the convenience of the participant. The interview was composed of eleven main questions, with some 
of the questions having additional probing questions that were designed to stimulate and deepen the conversation.

\section{Data Analysis}

The qualitative data was analyzed by entering, interpreting, verifying, representing and illustrating the text (Greenhalgh et al., 2005). I transcribed the audio recordings and summarized each participant's narrative in their own words onto four pages. I removed everything but the crucial elements of their stories and considered the responses given by each participant for each question. I listened to the recordings several times to make sure everything was correctly transcribed, and nothing was left out. I used a program called Otter, which is an electronic transcribing service. I reread the transcripts again and wrote out my thoughts and insights about the data into a memo file attached to the participant's narrative file and then coded these insights (Hunter, 2010). I summarized each participant's story and then coded the data into themes and sub-themes.

I identified common themes, thoughts and patterns that were presented across all the stories (Riessman, 2008). I then explored the data in terms of participant's narratives, looking for similarities between narratives and how it related to the information that was presented in the literature review. The themes and sub-themes were identified based on the amount of supporting evidence and then rewritten in its final form. I then drew conclusions about what the results may mean for this particular research, as well as the implications for future research.

\section{Ethical Consideration}

This research was intended to be of very minimal risk to participants. During the interviews there was the risk that participants could experience discomfort or embarrassment while disclosing 
their experiences in accessing services. However, this risk was low because these individuals have experienced life and there is support available to cope with their stressors and feelings. No identifying information is included in the completed research publication. The participants were reminded that their participation is voluntary and that they could withdraw at any time without consequence. None of the participants chose to withdraw from the study. All demographic data was stored securely in a password protected file and will be destroyed in a timely manner. Participants were asked to review and edit their interview transcripts, as well as approve the final research paper to ensure they were comfortable with the information and data present. Pseudonyms are used in this MRP to prevent identification and the findings were made available to participants. 


\section{CHAPTER 5. FINDINGS}

In this chapter I will highlight the narratives that emerged out of the three interviews conducted with participants. All three participants were from East Africa of Swahili ethnic origins. To protect their identities, the participants chose their own pseudonyms and those findings that are included in this chapter were selected based on their relevance in answering the research questions. I am very grateful for my participants who shared their experiences, time and contribution to my research project.

\section{Participants}

Hassan is a 68-year-old man from Tanzania, who immigrated to Canada in 1996. He is single and lives by himself in a one-bedroom apartment. Hassan is a retiree and due to his ill condition, he is looking to move into long term care facilities.

\section{Nathoo}

Nathoo is an 85-year-old man from Tanzania. He is of Indian origin and lives by himself. His wife passed away a few years ago. He has a child and grandchildren who live outside of Toronto. Nathoo is a retiree and relies on his pension benefits as his source of income.

\section{Saada}

Saada is a mother of three children. She is 72 years old and from Kenya. She used to work in different long-time care facilities as a personal support worker. She is now living with her eldest daughter.

\section{Themes}


The narratives of my participants will be discussed according to themes that emerged from the data. In addition to these narratives, I will incorporate some of my thoughts and reflections.

\section{Views on Long Term Care Facilities}

All participants identified as "racialized minorities" and experienced a lack of services and attention to their needs as seniors. The male participants, Hassan and Nathoo, seemed to welcome moving into the long-term care facilities more than Saada, the woman participant.

Hassan expressed his feelings:

I want to get in sooner not later because I feel lonely in here. I am worried each day on what is going to happen when I get sick and I am [in]capable of taking care of myself. It is really a scary situation when I think of dying here because there is no one present to help me in times of need. I watch people old like me who lives alone, and I got this bad feeling.

Hassan also talks about the service:

I don't really care if I end up in long term care, but a lot of mistakes happens in there [sigh] and it is so weird.... that I feel there are not really service for elders of racialized minority. I struggle to decide on where to go.

In the above passages Hassan articulates an ambivalence towards long term care facilities.

While on one hand, he desires to get into a LTCF as soon as possible, he understands that a lot of mistakes happen within these facilities.

Nathoo has this to say,

Umm for now I can say I am old, very old and I thank the government for having my benefit so I can manage to have someone like a 'caregiver' to come in here and clean the house and cook for me sometimes. I am lucky to have this privilege of home care. I would love to be in a retired home or long-term care facility, but I am scared, I don't know why.

Unlike Nathoo, Saada explains this from her experience as someone who used to work in long term care facilities:

Things need to be done sooner for people like us when we have to go to these long-term care facilities [sigh] lack of services...for me through my experience 
[sigh] there are no services directly designed to address the issues of the service users especially racialized minorities. I worked in many long-term care facilities and I am telling you now...uhm it is difficult to live in those places [sigh] and it feels like to living in a prison for most of the time. Ooh I can't [sniffing] I am scared when I go in there, I feel like I would be dead soon.

Saada also adds:

In those facilities it is difficult when you are not capable to explain what you need in the English language, I went to school to learn English before I took a course as a personal support worker, but also I had to try be like Canadian and it is difficult culturally; everything is different, I could not assimilate into these western norms, but I can tell my grandchildren assimilate into the culture; they are different culture. This makes me feel really lost, not to get emotional support [sigh] I took care of my children and my grandchildren, but I wonder if they can afford to care for me in the future.

In the above passages, Saada highlights the carceral nature of LTCF and how difficult it can be to live in such settings. She also brings an awareness of how not being able to speak English poses problems for racialized seniors.

\section{Gender issues}

It seems that Nathoo and Hassan, the male participants, are more at ease to go to the facilities as long as there would be services that accommodate their needs. For their female counterpart, Saada, she is much more hesitant to go to a LTCF because of her prior work experiences in such facilities. Her work experience exposed her to the subpar services.

Saada explains her fear,

The service is horrible in there. I saw with my own eyes when these innocent people suffered in these facilities. For me, "cleanliness is next to Godliness" and this part is missing in the facilities. It takes a while for the elderly in those places to get a bath or a shower. I [sighed] cannot tolerate that, I would rather stay and die here at home surrounded by my family.

Saada continues to explain,

Back home we lived with our parents when they get old until God wants them, it is a great honour for the siblings to care and take responsibility either in turn or by agreement of who is going to live with the ailing parent, but here in Western 
culture everyone wants to live by themselves. It is sad [sigh] really sad to see these people feeling lonely in those facilities, while many of those people have big families that can take care of them, but I think we become more selfish.

Saada expressed her feelings of not wanting to go in the long term care facilities due to the "horrible" services, which she witnessed first hand. Conversely, Hassan and Nathoo were more ready and prepared to live in the facilities when their time comes as long as there would be services, programs and policies that would meet their needs and their demands.

Nathoo mentioned his feelings:

So far, I do not have any bad experiences since I got the home care services. I fell down in my bathroom and was there for more than eight hours. I thank God for being alive today and it is the efforts of the doctors and other health care workers that I am alive today and in good shape. I am happy with my life; I receive my pension and it helps in taking care of many things regarding my health. I am happy for what I receive now and when the time come for me to go to retired home or long-term care facilities, I think I am okay with it. I am in good spirit[laugh].

Hassan mentioned how the importance of having affordable long-term care facilities is important for people like him who is racialized and living in poverty:

As a racialized minority I feel the need of the government and the service provider to look beyond racial profile and accommodate us elders in need [sigh] I am not sure about my tomorrow. I worked hard since I came to this country, but I never got a decent job. I did not have enough to contribute to my pension and now I live in Toronto housing, at least can manage to pay my rent, but who knows? If I have to go to those facilities, I will go if there would be no discrimination because I am a racial minority.

\section{Barriers in accessing health care/systemic barriers}

In terms of accessing health care, all three participants acknowledged systemic barriers while trying to access adequate health care services for seniors. They also noted language, emotional and psychological effects as the main barriers preventing them from accessing LTCF. Also, the inability to communicate feelings with their service providers is another significant barrier to accessing appropriate health care services.

Nathoo states: 
I think everyday when I have to decide to move in the long-term care facility, it means I have to leave my belongings here at my home and go to live with total strangers. I feel a very negative reaction. [sigh]. I feel a very negative reaction sometimes. I am thankful now that I am in a good health care and insurance. When I fell in my bathroom, I spent a long time there[sigh] but the help came in, thank to Allah I can express myself, I have a good health coverage and insurance. I feel bad for those elders who have a language barrier, it is really hard to get the appropriate services because of lack of communication, not everyone is lucky, I feel sad.

Saada expresses her emotion:

I was a child myself and I took care of my parents and grandparents. This situation now changed, I don't know if my grandchildren would be able to live with me, time is not the same, aagh... everyone is busy here, but I don't want to die alone, when you struggle to try to explain, people don't listen, it hurts me emotionally, I can communicate when I want help but I feel sorry for those elders from racial minority who lack communication, the struggle is real, the service providers do not care, it effects these people psychologically. People here do not like to live together in a house as a big family. I am not used to be by myself. I feel scared even to think about it and I am really struggle with the situation.

Saada added:

The world we live now there is no respect for elders. I am in fear of telling my grandchildren on what they should do or should not do, I want to see them every day, but it is impossible. I saw a lot of elders that are struggling in the long-term care facilities because of loneliness. I do not want to be in that situation. Having to work with elders from diverse background developed my empathy and gave me an insight of what would be an appropriate way to serve or accommodate the racialized minorities. These people came from different cultures and are not used to Western culture and lifestyle. For us, home is the place to stay and be with family from children to grandchildren and greatgrandchildren, but the children who were born here all they think is work and work, how to get a job and everything else, I guess, for them is less important. I do not blame them but the system, [sigh] everyone is struggling.

In the above passage, Saada laments the ageism in our society that is manifested as a lack of respect for elders. She notes how isolating LTCF can be for so many racialized elders. Concomitantly, she expresses her longing to spend time with her children and grandchildren.

Hassan gives his thoughts: 
Umm.... Life is different now, I am old, I have no energy left to do everything. I am very emotional most of the time, and the more I think the more unstable I become, I am not crazy but psychologically I am not well. I become emotionally unstable when I have to answer many questions in terms of getting the services that I deserve a Canadian citizen. I feel discriminated for my age, ability as well as my race. This is unacceptable. We call here [sigh] diverse country but where is the diversity?

Hassan continues to express his emotions,

The more I think, the more unstable I become. I feel that at my age, I don't have much time left to live. I live here by myself and I am not comfortable to go to the long-term care facility because of their lack of support of what I need as a Muslim woman [sigh, laugh]. I really don't want to think or talk about it.

Hassan adds some point

The struggle is real, I did a lot of odd jobs since I moved herein did a lot of odd jobs since I moved here, I went to school to study law but getting a decent job was always a struggle. I feel discrimination everywhere. I didn't contribute much to the pension benefit, I will have to suffer the consequences.

In the above passages, Hassan candidly shares his struggles on a psychological level and how discrimination exacerbates the struggles in his life.

Nathoo has this to add,

As an immigrant, I have many traditions which is very opposite with the western culture such as food, clothes and religious activities such as prayers. When I think of leaving my belongings here at home, I feel anxious [sigh] frustration because I don't know what to expect in those places, that's why I hesitate. For now, the services I get at my home is fine with me.

Nathoo, not unlike Hassan and Saada, brings an acute awareness of how their cultures are not accommodated in LTCF. For Nathoo this creates much anxiety and frustration.

\section{Long term care facilities with same cultural background/diversity}

All three participants mentioned their expectation of having more long-term care facilities that specifically serve racialized minorities. Mainstream long-term care facilities are there but they lack appropriate services to accommodate the needs of racialized minority elders. All participants 
agreed that the need for care is there because they are in situations where they see themselves no longer being able to take care of themselves; additionally, they would prefer to be in a LTCF rather than being at home by themselves and feeling lonely.

The participants described several factors that contribute to their fear as service users not being able to access or get the long term care facilities according to their needs.

\section{Saada explains,}

It is important to be in a place that people can relate to each other, even though they came from different places, but cultural similarities would be very important. Where I came from, we do not put our elders in the facilities, we have to take care for them in the house. I see the same with Indians people here. There are so many people from South Asian origin, but there is no long term care facility specifically for them, because it is not their culture to do that. So we need to make sure that these facilities can accommodate our needs.

Hassan says the following about cultural background:

I feel happy when I meet people that speak my language or have a similar culture and tradition, the cultural context for us Swahili people are very important. I think it is easier to relate and connect when people are from the same cultural background.

He added that,

I am Muslim and according to my religion, I have to pray five times a day. Where would I get a space that can accommodate my needs of doing my prayers peacefully? I need water to purify my body, but here people do not use water frequently for clarifying their bodies; it is so stressful to think about it. I don't want women to come and take care of me, touch me, see me naked. Regarding the food, I need the food that I like to eat, would there be a choice? [Big sigh] No I don't think so.

All three participants were fearful of the lack of spaces within the facilities for these ethnocultural people to practice their religion or to participate in their traditional or cultural activities.

\section{Policies}


All three participants shared their thoughts regarding the existing policies. They noted the increasing number of seniors in Canada and the pressing need for the government to respond to seniors in a way that considers the diversity within this population.

Saada said,

I have seen a lot in my working days. Here in Canada [sigh] regardless of where you came from, you have to live like Canadian people, it is a norm and expectation. I realized that most of the long-term care facilities are functioning in western ways on their rules, regulation, the settings of the facilities. The service providers rarely know about the different needs of their service users. It is really hard for people of racialized minorities as myself. I feel isolated if I go in those facilities.

Nathoo has this to say,

I think the government needs to address the issues regarding elders particularly from racialized minorities because as we getting [older] we need more health care service and as these facilities have specific model of giving the services and it is western way of giving the services, if I go to retirement home or in one of these long term care facilities, I think these places should be open to all races and there should be no discrimination. I want to do my own activities such as exercises and gym [laugh]. I want to see my family and friends; out there I will have no one, this condition will give me stress and depression.

Saada added,

I hope these people from the government knows that elders are getting big in numbers every year and the needs for services will increase to these population, so I think the government will consider these needs for our people and trying to satisfy those important needs; the old person needs is care, good care. The service provider should have better understanding of these need from the racialized minority elders and be able to attend to those needs.

Hassan echoed the need for more government intervention in addressing the needs of racialized seniors, particularly for those who are living on limited incomes. He had this to add,

Government need to do more research regarding elders, there is need to train people and educate them so that they will have experience in serving different people who have different needs, now these people who works in the facilities [sigh] don't care about us, they have different attitudes, behaviours, barriers in receiving services are everywhere, the service users needs to respect the right of the people. All policies regarding elders should be revisited and renewed, right 
now accommodation is very expensive, many of us elders rely on social welfare, it is very difficult to share spaces with people from different culture. My living condition is uncertain, not having enough money for my needs is crucial part of my anxiety.

The above narratives from the participants highlight a desire for government policies that can respond to the heterogeneity within the population of seniors, including cultural and class differences.

\section{Thoughts and Recommendations}

All the participants shared their thoughts and recommendations for improving services for racialized elders so that many more would feel comfortable living in a LTCF. Hasan recommended policy change by the government and the health care service providers to take appropriate actions and measures to ensure that racialized elders receive the services appropriate to their cultural needs. He explained,

The government needs to change the policies, [sigh heavily]. The money should be a priority to build more housing; the government need to spend more money if they want a proper life for their elders. These policies need to accommodate the need of these racialized minority elders so that they feel happy and safe living in those facilities. The stories I hear now is horrible [sigh] and makes me anxious, scared even to think of moving there.

Nathoo made the recommendation that services for elders must be accessible in terms of language. He noted that seniors who do not speak English fluently may experience significant barriers to accessing services. He explains,

I think it would be helpful if the department concerned with welfare of the elders can work together with the government to see that these elders can get the services, they need that are culturally appropriate and without discrimination; [I] have not yet encounter problems of language, but I have many friends who feel uncomfortable to talk to the services providers due to language barriers. They can not share their problems because of shame. This is a big concern even for me. I would like to be in a place with the people I know, or I can easily talk to.

Saada has this to say, 
There is lack of culturally appropriate within many of the facilities, which leads to many problems such as elder abuse, and increase of health disparities for these population. I hope that in the near future the government will consider putting more funds in these facilities and to hire many diverse service providers, or to put funding for the home care services which I prefer.

In the next section I will delve deeper into an analysis of the narratives presented above. 


\section{CHAPTER 6}

\section{DISCUSSION AND ANALYSIS}

This chapter will provide an analysis of the narratives noted in the above section and conclude by outlining some recommendations for future studies. However, before I begin my discussion, it is important to note that my own identity may be influencing my interpretation of the findings. I am an immigrant woman of colour, who is middle aged and has a critical perspective on old age. While conducting this research, my experience in working with seniors from diverse backgrounds ignited my passion of wanting to explore and dig more deeply into the issues and services for this population. It surprised me to find that this topic has not been examined in depth or given much thought and priority by scholars, even among those from racialized minority backgrounds.

Both of the male participants, Nathoo and Hassan, had a common understanding regarding LTCF. However, they had little overall knowledge about long term care facilities and health care services for elders in Canada. Their lack of knowledge around LTCF is mirrored by the lack of research about racialized elders in Canada. Many of the articles that I reviewed were conducted by outsiders or researchers who are white. This often allows for dominant groups to marginalize groups by constructing the ways in which their cultural differences keep them secondary to Europeans (Razack et al., 2010). The default cultural norm is that of the western majority group, so when these experts do their research regarding minority groups, they often view different cultures as inferior and not up to their standards; yet they often do not acknowledge that cultures are different everywhere around the word, and here in Canada the diversity should be appreciated, instead of assuming that people will assimilate into Canadian culture. This lack of academic research focus on racialized elders is reflected in Nathoo and Hassan lack of knowledge about 
LTCF. As well, Saada's narrative also highlighted her concerns about the Eurocentric nature of LTCF.

The narratives of the participants also called for more culturally appropriate or ethnospecific LTCFs. The major contributing factor of not having enough ethno-specific LTCFs is the assumption that everyone is equal in terms of health care needs. In reality there are many obstacles in accessing long-term care including the requirements. I want to highlight the discrepancy for elders from racialized minority communities in accessing LTCF. The LTCF and the service providers are trying hard to facilitate the needs of their services users. However, many people from racial minority groups do not feel comfortable going into LTCF. This was evidenced in the narratives of the participants in this study. As well, many elders from the poorest countries who are not eligible for benefits continue to be impoverished and suffer in Canada (George \& George, 2013). This was evident in the narrative of Hassan, who immigrated here from Zanzibar. He does not have an adequate pension from his previous work places, and he noted that he also lacked the financial resources to pay for medication.

Hassan, Nathoo and Saada all insist on policy changes and the need to advocate for the creation of policies that would permit elders to receive adequate old age security or guaranteed income. They also recommended creating policies that would ensure that older adults from racialized backgrounds can receive more support and access to care.

The literature notes that many elders lack financial independence and rely on their adult children, which creates stressors that could in turn lead to intergenerational conflict and elder abuse (George \& George, 2013). I support asking the government to revitalize the value of human dignity as integral to social justice and equity and the need to adjust the inequitable Old Age Security (Gorge \& George, 2013). I have worked with seniors for many years in different environments, 
and I have seen a lot of problems in rules and regulations regarding seniors' services. As noted, by George and George (2013), an individual choice is limited through various mechanisms of governance such as policies and procedures.

\section{Racism as a barrier for obtaining health services}

Racism is one of several fundamental or basic social determinants of health, and it relates to both institutional and cultural racism (William \& Mohammed, 2013). Internalized racism can lead to low self-esteem and psychological harm, and this can be seen by many racialized minorities here in Canada, and in North America in general. Two of my participants emphasized the issue of racism and discrimination as barriers for them to obtain services. For many years, health professionals and other powerful societal entities perpetuated the concept of race and linked it to the biological makeup of individuals (Gary, 2005). Race is a social construct that has powerful and sometimes devastating consequences. Again, as a middle aged woman of colour, I know what racism is through experience. It is all over the world and it predates colonialism; it is not only a black and white issue, but race is elastic and an ever-changing social construct. I did recognize and discuss systemic racism in the place where I worked, as well, I volunteered and genuinely aimed to accept and help people for who they are.

\section{Marginalization of racialized minorities}

Many elders from racialized minority communities came to Canada as a caregiver, immigrant, or with refugee status. Some find themselves too old to upgrade their skills and acquire Canadian experience which is required to find a decent job. As a result, these people were not able

to make sufficient contributions to their old age security or due to a lack of personal savings are 
now living in poverty or are reliant on social assistance and/or ODSB; this was discussed in the narratives of Hassan and Saada.

By doing this study I learned various anti-oppressive practice (AOP) concepts particularly essentialization, whiteness and reflexivity; these were the main concepts that were relevant to my experience, helping me to identify the complex power structures in Canada. The concept of whiteness made me recognize how whiteness can be embedded throughout society. Society is based upon racial categories, such as black, white, Asian and Indigenous. Social inequality occurs in all societies; even here in Canada, the evidence is overwhelming that discrimination is widespread and systemic. The social system is linked by transactions, where individuals must engage together because other individuals have control of the resources they need (Connell, 2007). This is a power dynamic characterizes the encounters between service providers and service users. This power is often used to discipline service users. Discipline always operates as an economy of power. It is a means of distinguishing, separating out, and sorting individual bodies from the mass of humanity (Moffatt, 1999). This situation addresses the oppression that the recipient may feel towards the service provider and the lack of acknowledgement. Browne (2005) addressed how there are many forms of oppression, and how they work together to produce injustice, which in this case takes the form of the service users feeling isolated and unwanted. This self-reflexive process helped me grow as a concerned citizen and motivates me to help those in need such as elders. I intend to raise awareness about unmarked issues and challenges so that we can create more equitable services for racialized elders. This will be my contribution to the social work profession.

\section{Social Differentiation}


In society, social differentiation is inseparable from inequality, which characterize the economic and social order (Juteau, 2000). Unequal access to economic and educational opportunities and the negative perceptions accompanying minority status, serve to create and reinforce negative variation, which is happening in Canada. Even though we embrace diversity and multiculturalism, we are far from making this a reality. In this country, racialized individuals are often seen as deviating from the norm, as not fitting in, and generally speaking, as possessing less value (Juteau, 2000). Juteau (2000) mentioned that many factors create barriers to employment and social mobility for non-white Canadians, especially immigrants. As an immigrant and woman of colour, I have encountered many of these barriers on many different occasions. Policies are embedded in value and normative standards, which provide a framework for definition of issues, priorities, the legitimization of choices and the institutionalization of social differentiation (Juteau, 2000). This needs to be highly considered and contested if society wants to benefit all citizens equally.

As a form of neoliberal governmentality, we have individualized ideas based on charity and survival through becoming "responsibilized" (Janzen, Jeffrey, \& Smith, 2015). To be a good citizen and be on the priority list, you need to contribute more to the community than what you are getting out of it. With this notion in mind, most social welfare recipients, including elders from racialized minority groups, would be seen as "bad" or unworthy citizens. The recipients of social services are routinely subjected to intrusive surveillance by service providers who determine their eligibility and benefit levels (Myles \& Pierson, 1997). The result of this is that most recipients including vulnerable elders get pushed out of the system. The narratives of Nathoo, Hassan, and Saada have clearly shown that racism, poverty, and ageism are oppressive social forces that they are contending with as racialized elders. They have spoken about a fearfulness of having to enter 
LTCFs that are not responsive to their cultural backgrounds and ethno-specific needs. They have also offered very important and insightful recommendations for policy changes. 


\section{CHAPTER 7}

\section{CONCLUSION}

This study aimed to identify the issues and approaches for serving Canada's immigrant elders from racialized minorities. This finding reflects what literature says about our elders and their perception of LTCF. In order to reflect the diverse voices and perspectives of these elders who experiences multiple systems of oppression such as racism, colonialism and other forms of oppressions, my goal would be for my study to be used to influence change in terms of serving these elders for their care and well-being. If we can help these elders to live in good health, we can improve their quality of lives which will also reduce the institutionalization for these vulnerable population. As of now much of our current aging related programs and policies treat our senior population as a homogeneous group, ignoring the diversity of needs, concerns, and experiences of seniors (Laher, 2017). Social workers and professionals need to push conversation regarding older adults, and to advocate for the equal access for the racialized minorities. I am immensely indebted to these three participants who shared their insights with me, which was essential for the success of this study.

\section{Limitations and future areas of study}

While the study gives the narratives of how the racialized minority elders perceive the services at LTCF there were some limitations to this study that are important to point out. Only three participants were interviewed in this study. Although I believe their narratives are extremely important there are still some voices that have not been heard, which would be an important addition to this study. This study was based on my own interest and my curiosity after finding that there are very few scholarly articles that focus on the racialized minority elders. As a researcher I gained the unique opportunity to gain knowledge and to get to listen to the narratives of the elders 
from the same background. Many of these scholars are the outsiders, while I consider myself as an insider. I recommend that future areas of study should be done in this particular area that would include many participants from different part of the world and are considered racialized minorities.

Although themes and analysis accurately represented the participant's narratives, I realized that there were some difficulties in transcription. Although we were conducting the interview in the English language, I did not get accuracy of the words from my participants when I was transcribing. I tried to be critically reflexive and be more open with my participants, but I hope future studies will include mother tongue language which will make the conversation smoother and more nuanced.

Whether we need more mainstream LTCF for these elders from racialized and ethnic communities, LTCF is something to consider in strengthening the gerontological curriculum in our social work education. Future research should also explore the possible benefits of having ethnic-specific LTCF to better serve the needs of racialized minority elders. Some of these elders prefer to live at home with their families, so the idea of having more home health care should be put into consideration for the future research.

I would like to conclude by expressing my respect and gratitude to the participants that contribute to this study which would not be possible if not for them and their thoughts and experiences which gives me so much insights and sense of being in the place of people who wants to dedicate their lives for helping others.

\section{Implication for social work and professional practice}

There were some recommendations that were provided by participants that needs to be taken into consideration including the suggestion that there should be a guideline for providers to 
be able to provide culturally appropriate care that focuses on ethnic population to reduce racial and health disparities. The narratives of the participants demonstrated their lived experiences and expressed their stories on systemic barriers, marginalized and oppression. Also, they advised on how to move forward and be ready to serve the elders in more appropriate ways by listening to their needs.

As professionals the need is there to make changes to the systems and deconstruct policies that create barriers for the racialized minorities because AOP works to seek fundamental change in the structures that perpetuates oppression (Parada et al., 2011). We need to be more reflexive and not to exercise power over our service users. As professionals we need to condemn all forms of oppressions and face the challenges; some of these challenges are our values and beliefs as well as experiences in working with diverse population. We must acknowledge our bias and assumptions for the purpose of challenge the oppressive structures in our society. The elders are marginalized population that faces a great deal of discrimination and oppression, and for most part we as professionals have acted as agents of social control, in doing so we play the role of dominant discourses and use our power as the provider to oppress these individuals.

We need to raise our voices and address the service gap for these populations, and we need to advocate for change and take steps forward to help our elders in achieving the services that are appropriate for their needs.

As social workers we need to challenge the rules and regulations that serve to oppress and marginalize our elders in general and to ensure that they get the best service and proper access to resources. We also need to ensure that they live with dignity and respect. As a social worker we emancipate people in their oppression and help them to achieve social justice, so our primary consideration should be always the service user. We do not have to think that the only challenge 
that social workers faces are helping those who asked to receive help, but the main challenge is to interact with those who need help in socially just ways. We need to focus, be reflexive and take appropriate action as AOP social workers who believes in justice, equality and diversity.

It is important to know when dealing with service users that they do not want to know about theory; it is our job as AOP social workers to know the population and what resources are out there to help them; we must do it in a critical stand point. The challenges that might come through are different for each service user, because every individual is unique. Through the knowledge of power, privilege and oppression we need to dedicate ourselves to improve social conditions and to enhance the quality of life of the marginalized and oppressed population.

All the policies should be made in reflection of the needs of the citizen, or in this case, the racialized elders. These marginalized people need to raise their voices through social movements to demand action and social justice in order to reform policies, so they no longer maintain the status quo.

My hopes are that my MRP may offer some insights into policy formation, especially around making services for racialized elders more equitable and accessible. Many members of racialized communities have very little knowledge about LTCF and have very negative perceptions and attitudes about them. It is imperative to identify culturally appropriate interventions in dealing with the issues of serving these elders. 


\section{Appendices}

\section{Appendix A}

\section{Ryerson University Consent Agreement}

You are being invited to participate in a research study. Please read this consent form so that you understand what your participation will involve. Before you consent to participate, please ask any questions to be sure you understand what your participation will involve.

TITLE OF THE STUDY: Racialized Elders: Issues and approaches for serving Canada's immigrant elders

INVESTIGATORS: This research study is being conducted by Arafat Mustafa and supervised by Gordon Pon, from the School of Social Work at Ryerson University.

If you have any questions or concerns about the research, please feel free to contact Arafat Mustafa; arafat.mustafa@ryerson.ca or Gordon Pon; g2pon@ yerson.ca

\section{PURPOSE OF THE STUDY:}

The purpose of this study is to explore the barriers and lack of services faced by racialized minorities from immigrant populations specifically accessing long-term care facilities. This work will utilize a critical lens in analyzing structural inequality, systemic barriers and the social construction of aging and the implication of social work practice.

This study will involve interviews with 2-3 racialized immigrant elders who are not in long-term care facilities, but expect to require these services in the future.

The results of this research will be used in the completion of the researcher's Master of Social Work as part of their Major Research Paper.

WHAT PARTICIPATION MEANS: If you volunteer to participate in this study, you will be asked to do the following things:

Research Participation:

- Participate in a one-time interview that will last approximately 2-3 hours

- The location of the interview will be selected based on the mutual convenience of you as the participant, and myself as the researcher

- Phone interviews will be an option depending on distance

Interview Content:

- Major research questions:

- What are the experiences of racialized immigrant elders in the Greater Toronto Area with respect to accessing and/or receiving services?

- Are there barriers that prevent racialized elders from immigrant populations from accessing long-term care facilities in the Greater Toronto Area? 
Research availability:

- $\quad$ Research findings and the final report will be made available to you in the Fall of 2019. I will contact you via email to inquire as to whether you would like a final copy of the report sent to you electronically.

\section{POTENTIAL BENEFITS:}

You will derive no direct benefits from your involvement in the project, beyond some potential satisfaction in knowing that your insights may help to highlight how the systems of long term care facilities can be improved to meet the needs of racialized seniors.

I cannot guarantee, however, that you will receive any benefits from participating in this study.

This research builds on and contributes to the understanding how the system works and will allow a space to not only examine the relevance of the voice of the elderly population, but also will educate the public and build awareness of prevalent stereotypes towards the aging population in Canada. This research will examine the issues of aging and the aging process in relation to structures, dominant discourses and unequal power distribution. The research will seek to investigate the policy gap on the role of caregivers and service providers in health care facilities.

\section{WHAT ARE THE POTENTIAL RISKS TO YOU AS A PARTICIPANT:}

There are minimal risks anticipated for your participation in this study. There is some social risk involved in critiquing the services.

There will be steps taken to mitigate these risks. Confidentiality will be strictly upheld in this study, and your name, research projects and institution of employment will be given pseudonyms. Your participation, including specific elements of your interviews, can be withdrawn from the study at any time prior to completion. However, after March 30, 2019, you will not be able to withdraw your data from the study because it will have been integrated into the overall analyses of the data. You will be informed of the potential of these risks prior to beginning the interview and will be informed that you may skip any interview question, either temporarily or permanently. Direct quotations included in the report will not include any information that would enable a reader to identify the source.

\section{CONFIDENTIALITY:}

We will protect your confidentiality and any other individuals named in the interviews by (1) storing the data in a secure, password-protected electronic file that can be accessed only by the Principal Investigator, (2) replacing your name and affiliated institutions on documents with pseudonyms for the purposes of data analysis and in any public documentation, (3) storing the master sheet of names with their corresponding pseudonyms in the password-protected file, and (4) only identifying the source of quotations or ideas reported in research documents with your specific consent after vetting the text in question. 
With your permission, the interviews will be audio-recorded. Only the primary researcher will have access to the raw and transcribed recordings. You have the right to access and review the recordings and their corresponding transcripts at any time and will receive an email with your completed transcript for your review. Notes and recordings will be kept until the completion and approval of the MRP by the supervisor and second reader. All data will then be shredded and/or deleted. Notes and recordings of the interviews will be available to and used only by the primary researcher and will not be played or made available to the public or anyone outside of the researcher.

\section{VOLUNTARY PARTICIPATION AND WITHDRAWAL:}

Participation in this study is completely voluntary. You can choose whether to be in this study or not. If any question makes you uncomfortable, you can skip that question. If you choose to stop participating, you may also choose to not have your data included in the study. However, after March 30, 2019, you will not be able to withdraw your data from the study because it will have been integrated into the overall analyses of the data. Your choice of whether or not to participate will not influence your future relations with Ryerson University or the investigator involved in the research.

QUESTIONS ABOUT THE STUDY: If you have any questions about the research now, please ask. If you have questions later about the research, you may contact: Arafat Mustafa arafat.mustafa@ryerson.ca or Gordon Pon g2pon@ryerson.ca

This study has been reviewed by the Ryerson University Research Ethics Board. If you have questions regarding your rights as a participant in this study, please contact:

Research Ethics Board

c/o Office of the Vice President, Research and Innovation Ryerson University

350 Victoria Street

Toronto, ON M5B 2K3

416-979-5042

rebchair@ryerson.ca

\section{CONFIRMATION OF AGREEMENT:}

By signing this consent form, you are not waiving your legal rights or releasing the investigator(s) or involved institution(s) from their ethical, legal or professional responsibilities.

I have read and I understand the above information about a study being conducted by Arafat Mustafa under the supervision of Gordon Pon of the School of Social Work at Ryerson University. I have had the opportunity to ask questions related to this study and to receive satisfactory answers to my questions. 
- I am aware that I have the option of not allowing my interview to be audio recorded.

- I am also aware that excerpts from the interview may be included in publications to come from this research, with the understanding that the quotations will be anonymous.

- I was informed that I may withdraw my consent at any time without penalty by advising the researcher.

With full knowledge of all foregoing, I agree, of my own free will, to participate in this study.

$\square$ YES $\square$ NO

I agree to the use of anonymous quotations in any publication that comes of this research.

$\square$ YES $\square$ NO

I agree to be named in the final copy of the thesis. (Please note that by agreeing to be named, you will not have the level of confidentiality protection that you would have if you remained anonymous)

$\square$ YES $\square$ NO

I agree for my research project to be named in the final copy of the thesis. (Please note that by agreeing to have your project named, you will not have the level of confidentiality protection that you would have if your project remained unnamed)

$\square$ YES $\square$ NO

I agree to have my interview audio recorded. $\quad \square$ YES $\square$ NO

Participant Name: __ (Please print)

Signature:

Date 
Appendix B

Project Title: "Racialized Minorities" issues and approaches for serving Canada's immigrant elders

Researcher: Arafat Mustafa; arafat.mustafa@ryerson.ca

Faculty Advisor: Gordon Pon, School of Social Work (416-979-5000 ext. 4786);

g2pon@ryerson.ca

\section{Interview Questions}

1. Can you please tell me a bit about yourself? Where were you born? How old are you? When did you come to Canada? What language do you speak?

2. What have your experiences been of accessing and receiving services as a racialized elder?

3. Do you experience any lack of facilities and barriers of receiving service as an elder within an immigrant population?

4. What are your thoughts around the demand for long-term care services in Ontario?

5. Are there cultural differences between how your culture views long term care and Western views on long term care?

6. I understand that you are currently not in long-term care? Can you tell me about this situation? How has your decision not to enter a long-term care facility impacted your life choices?

7. Do you have recommendations for long term care facilities that will help them be appropriate and accommodating of racialized minorities?

8. What do you see as the benefit of having culturally appropriate care for the elderly?

9. How do you believe current policies have impacted your experience as an elder within an immigrant population?

10. What recommendations would you make to promote appropriate long-term care for racialized minorities?

11. Is there anything else we have not touched on that you think is worth noting or discussing? 


\section{References}

Altman, S. S. \& Cohen, M. (2009). Nursing aides 'attitudes to elder abuse in nursing homes: The effect of work stressors and burnout. The Gerontologist, 49(5), 674-684.

Alshenqeeti, H. (2014). Interviewing as a data Collection Method: A critical review. English linguistic research, 3(1). Doi: 10.5430/elr. v3n1p39

Bauer, M., McAuliffe, L., \& Nay, R. (2007). Sexuality, health care and the older person: An overview of the literature. International Journal of Older People Nursing, 2(1), 63-68.

Baines, D., (2011). An overview of anti-oppressive social work practice: Neoliberalism, inequality and change. In D. Baines, (Ed.) Doing anti-oppressive practice: Social justice social work (pp. 25-47). Halifax: Fernwood Press.

Baines, D. (2007). Anti-oppressive social work practice: Fighting for space, fighting for change. In D. Baines (Ed.). Doing anti-oppressive practice: Building transformative, politicized social work (pp. 13-42). Halifax: Fernwood

Baines, S., \& Edwards, J. (2015). Considering the ways in which anti-oppressive practice principles can inform health research. The Arts in Psychotherapy, 42, 28-34. doi:10.1016/j.aip.2015.01.001

Banerjee, A., Daly, T., Armstrong, P., Szebehely, M., Armstrong, H., \& Lafrance, S. (2012). Structural violence in long- term, residential care for older people: Comparing Canada and Scandinavia. Social Science \& Medicine, 74(3), 390-398.

doi:10.1016/j.socscimed.2011.10.037

Berg, b. L. (2007). Qualitative research methods for the social sciences. London: Pearson.

Browne, S. (2015). Introduction and other dark matters. In dark matters: On the surveillance of blackness, pp. 1-29. Durham and London: Duke University Press.

Brozowski, K., \& Hall, D. R. (2010). Aging and Risk: physical and sexual abuse of elders in Canada. Journal of Interpersonal Violence, 25(7), 1183-1199.

Brown, L. A., \& Strega, S. (2005). Research as resistance: Critical, Indigenous and Anti Oppressive Approaches. Toronto, CA: Canadian Scholars' Press.

Charmaz, K. (2017). The power of constructivist grounded theory for critical inquiry. Qualitative Inquiry, 23(1), 34-45.

Chase, S.E., (1996). Personal vulnerability and interpretative authority in narrative research. In R. Josselson (Ed.), Ethics and Process in the narrative study of lives (pp. 45-59). Thousand Oaks, CA: Sage.

Chase, S. E., (2003). Learning to listen: Narrative principles in a qualitative research methods course. In R. Josselson, A. Lieblich; D. P. McAdams (Eds.) Up close and personal: The 
teaching and learning of narrative research (pp. 79-99). Washington, DC: American Psychological Association.

Chase, S. E., (2005). Narrative inquiry: Multiple lenses, approaches, voices. In N. K. Denzin \& Y. S. Lincoln (Eds.), The Sage handbook of qualitative research (3rd Ed), pp. 651-679. Thousand Oaks, CA: Sage Publications

Clandinin, D. J., \& Connelly, F.M., (2000). What do narrative Inquirers do? In Narrative Inquiry: Experience and Story in Qualitative Research (p. 48-62). San Francisco, CA: Jossey-Bass

Cohen, L., Manion, L., \& Morison, K. (2007). Research Methods in Education. (6th ed.). London: Routledge.

Connell, R. (2007). Chapter Two. Modern general theory and its hidden assumptions. In Southern Theory, pp. 27-48; 233-261. Malden: Polity Press

Creswell, J.W., (2013). Five Qualitative Approaches to Inquiry. In Qualitative Inquiry and Research Design (3rd. Ed.) pp. 69-110. Thousand Oaks, California: Sage Publications

Creswell, J.W., (2007). Qualitative inquiry and research design: Choosing among five Approaches (2nd ed). Thousand Oaks, CA: Sage.

Creswell, J. W., (2008). Narrative research designs. Educational research: Planning, conducting and evaluating quantitative and qualitative research (3rd ed), pp. 511-550. Upper Saddle River, NJ: Pearson Education, Inc.

Denzin, N. K. and Lincoln, Y. S., (2005). The discipline and practice of qualitative research. In N. K. Denzin and Y. S. Lincoln (Eds.), Handbook of qualitative research (2nd Ed.) (pp. 1 28). Thousand Oaks, CA: Sage.

Dossa, P.A. (1999). Journal of Cross-Cultural Gerontology 14: 245. https://doiorg.ezproxy.lib.ryerson.ca/10.1023/A:1006659904679

Fraser, H. (2004). Doing narrative research: Analyzing stories line by line. Qualitative Social Work, 3(2), 179-201.

Gary, F. (2005). Stigma: Barrier to mental health care among ethnic minorities. Issues in Mental Health Nursing, 26(10), 979-999.

Janzen, C., Jeffrey, D. \& Smith, K. (Eds). (2015). Introduction. Encounters with Difference in a Neoliberal Context. In C. Janzen, D. Jeffrey, \& K, Smith (Eds), Unravelling Encounters: Ethics, Knowledge, and Resistance under Neoliberalism. Pp. 1-19. Wilfred Laurier Press.

Juteau, D. (2000). Patterns of Social Differentiation in Canada: Understanding Their Dynamics and Bridging the Gaps. Canadian Public Policy / Analyse De Politiques, 26, S95-S107. doi: $10.2307 / 3552573$

Ladson-Billings, G., (2003). Racialized Discourses and Ethnic Epistemologies. In N. Denzin \& Lincoln (Eds.). Handbook of qualitative research. California: Sage. 
Ladson- Billings, G. (2000). Handbook of qualitative research. Thousand oaks, CA: Sage Publications. (pp. 257-277).

Laher, N. (2017). Diversity, Aging, and Intersectionality in Ontario Home Care. Why we need an intersectional approach to respond to home care needs. Wellesley Institute.

Fabbre, V. D., Buffington, A. S., Altfeld, S. J., Shier, G. E., \& Golden, R. L. (2011). Social work and transitions of care: Observations from an intervention for older adults. Journal of Gerontological Social Work, 54(6), 615-626. doi:10.1080/01634372.2011.589100

George, P., \& George, J. (2013). Interrogating the neoliberal governmentality of the old age security act: The case of sponsored immigrant seniors. Canadian Social Work Review/Revue Canadienne de Service Social, 30(1), 65-81. Retrieved from http://ezproxy.lib.ucalgary.ca/login?url=http://search.proquest.com/docview/1684422175?a ccountid=9838\%0Ahttp://dc8qa4cy3n.search.serialssolutions.com/?ctx_ver=Z39.882004\&ctx_enc=info:ofi/enc:UTF

Gele, A. \& Harsløf, I. (2012). Barriers and Facilitators to Civic Engagement Among Elderly African Immigrants in Oslo. Journal of Immigrant and Minority Health, 14(1), 166-174.

Global Health and Aging - World Health Organization. Retrieved from http://www.who.int/ageing/publications/global_health.pdf

Greenhalgh T, Russell J, Swinglehurst D. (2005). Narrative methods in quality improvement research. BMJ Quality \& Safety, 14:443-449.

Guruge, S. \& Thomson, M. S. \& Seifi, S. G. (2015). Mental Health and Service Issues Faced by Older Immigrants in Canada: A Scoping Review. Canadian Journal on Aging / La Revue Canadienne du vieillissement, 34(4), 431-444. Retrieved November 1, 2018, from Project MUSE database

Hullett, J. (2004). The United States Center for Disease Control and Prevention.

Hunter, M. (2002). Rethinking epistemology, methodology, and racism: or, is White sociology really dead? Race \& Society, 119-138.

Hunter, Sally V. (2010). Analysing and representing narrative data: The long and winding road, Current Narratives, 2, 44-54. Available at:https://ro.uow.edu.au/current narratives/vol1/iss $2 / 5$

Kaplan, S.A., Ahmed, R. \& Musah, A. (2015). "When you walk in the rain", Journal of Immigrant Minority Health, 17: 255. https://doi.org/10.1007/s10903-013-9873-x

Katz, S., \& Calasanti, T. (2015). Critical perspectives on successful aging: Does it "appeal more than it illuminates"? Gerontologist, 55(1), 26-33. http://doi.org/10.1093/geront/gnu027

Koehn, S., Neysmith, S., Kobayashi, K., \& Khamisa, H. (2013). Revealing the shape of knowledge using an intersectionality lens: Results of a scoping review on the health and 
health care of ethnocultural minority older adults. Ageing and Society, 33(3), 437-464. doi: 10.1017/S011686X12000013.

Mathebane, M. S., \& Sekudu, J. (2018). A contrapuntal epistemology for social work: An Afrocentric perspective. International Social Work, 61(6), 1154-1168.

Massaquoi, N. (2011). Crossing boundaries to radicalize social work practice and education. In D. Baines (ed.), Doing Anti-Oppressive Social Work. Winnipeg: Fernwood Publishing.

Matsuoka, A., Beaulieu, M., \& Kitchen, B. (2013). Strengths and flaws of aging policies in Canada. Canadian Review of Social Policy, 68, 12-II, III, IV, V, VI, VII, VIII,IX,X,XI,XII,XIII. Retrieved from http://search.proquest.com.ezproxy.torontopubliclibrary.ca/docview/1370183777?account $\mathrm{id}=14369$

Matsuoka, A., Guruge, S., Koehn, S., Beaulieu, M., \& Ploeg, J. (2013). Prevention of abuse of older women in the post-migration context in Canada. Canadian Review of Social Policy, 68, 107-120. Retrieved from http://search.proquest.com.ezproxy.torontopubliclibrary.ca/docview/1370183847?account $\mathrm{id}=14369$

Miner, S., Liebel, D.V., Wilde, M.H. et al. Journal of Immigrant Minority Health, 20: 1215. https://doi-org.ezproxy.lib.ryerson.ca/10.1007/s10903-017-0658-5

Moen, T. (2006). Reflections on the Narrative Research Approach. International Journal of Qualitative Methods, 56-69. https://doi.org/10.1177/160940690600500405

Moffatt, K. (1999). Reading Foucault for social work. New York, NY: Columbia University Press. (pp. 219-242).

Mullaly, B. (2010). Challenging Oppression and Confronting Privilege. Don Mills, ON: Oxford University Press

Myles, J., \& Pierson, P. (1997). Friedman's Revenge: The Reform of "Liberal” Welfare States in Canada and the United States. Politics \& Society, 25(4), 443-472. https://doi.org/10.1177/0032329297025004004

Neuman, W.L., (2000). Social Research Methods: Qualitative and Quantitative approaches. (4th Ed.). Boston; Toronto: Allyn and Bacon

Ng, E., Lai, D.W.L., Rudner, A. T., Orpana, H.T. (2012). What do we know about immigrant seniors aging in Canada? CERIS Working Papers, 88-90, 1-77.

Norris, J. E., \& Tindale, J. A. (2003). An intergenerational family systems model of problem gambling in later life: Final report to the Ontario Problem Gambling Research Centre. Unpublished manuscript. University of Guelph, Ontario.

Parada, H., Barnoff L., Moffatt K., \& Coleman, B. (2011). Promoting Community Change: Making It Happen in the Real World. Toronto: Nelson Education. 
Pon, G., Giwa, S., \& Razack, N. (2016). Foundations of anti-racist/anti-oppressive social work practice. In Al-Krenin and Graham, J. (Eds.) Diversity and social work in Canada (pp. 38-58). Don Mills, ON: Oxford University Press.

Potts, Karen, \& Brown, Leslie (2005). Becoming an anti-oppressive researcher. In L. Brown \&S. Strega (Eds.), Research as Resistance: critical, indigenous and anti-oppressive approaches (pp. 255-286). Toronto: Canadian Scholars' Press

Razack, S., Smith, M., \& Thobani, S. (2010). States of race: Critical race feminism for the 21st century. Toronto: Between the Lines.

Riessman, C.K., (2008). Narrative methods in social sciences. Los Angeles CA: Sage.

Riessman, C. K., \& Quinney, L. (2005). Narrative in Social Work: A Critical Review. Qualitative Social Work, 4(4), 391-412. https://doi.org/10.1177/1473325005058643

Riessman, C. K., (2008). Narrative Methods for the Human Sciences. Thousand Oaks: SAGE Publications

Rockwood, K., Song, X., \& Mitnitski, A. (2011). Changes in relative fitness and frailty across the adult lifespan: evidence from the Canadian National Population Health Survey. CMAJ: Canadian Medical Association journal = journal de l'Association medicale Canadienne, 183(8), E487-E494. doi:10.1503/cmaj.101271

Sakamoto, I. (2007). An anti-oppressive approach to cultural competence. Canadian Social Work Review / Revue Canadienne De Service Social, 24(1), 105-114. Retrieved from http://www.jstor.org/stable/41669865

Sarah Miner, Dianne V. Liebel, Mary H. Wilde, Jennifer K. Carrol, Sadiya Omar. (2018).Somali Older adults' and Their Families' Perceptions of Adult Home Health Services. J. Immigrants Minority Health, 20: 1215-1221

Senior Journal. (2005). Senior citizens gamble big and often. Retrieved May 19, 2007

Schwandt, T. A., (2007). "Literary turn (in social science)" and "Writing strategies" [Dictionary entries]. The Sage dictionary of qualitative inquiry (3rd ed., pp. 179-80, 322). Thousand Oaks, CA: Sage Publications.

Sethi, B., Williams, A., Desjardins, E., Zhu, H., \& Shen, E. (2018). Family conflict and future concerns: Opportunities for social workers to better support Chinese immigrant caregiver employees. Journal of Gerontological Social Work, 61(4), 375-392.

Stewart, M., Shizha, E., Makwarimba, E., Spitzer, D., Khalema, E., \& Nsaliwe, C. (2011). Challenges and Barriers to services for Immigrant Seniors in Canada: "you are among others, but you feel alone". International Journal of Migration, Health and Social Care, 7(1), 16-32. 
Sibbald, B., \& Holroyd-Leduc, J. M. (2012). Protecting our most vulnerable elders from abuse. CMAJ: Canadian Medical Association journal = journal de l' Association medicale Canadienne, 184(16), 1763. doi:10.1503/cmaj.121472

Statistics Canada. (2015). Canada's population estimates: Age and sex, July 1, 2015. Retrieved from http://www.statcan.gc.ca/daily-quotidien/150929/dq150929b-eng.htm

Statistic Canada. (2009) Retrieved From https://www150.statcan.gc.ca/n1/en/pub/11-402x/2010000/pdf/population-eng.pdf?st=grXFTOVm

Small, J., Chan, S., Drance, E., Globerman, J., Hulko, W., O’Connor, D., \& Ho, L. (2015). Verbal and nonverbal indicators of quality of communication between care staff and residents in ethnoculturally and linguistically diverse long-term care settings. Journal of Cross-Cultural Gerontology, 30(3), 285-304. Doi: 10.1007/s10823-015-9269-6

Spencer, C., \& Soden, A. (2007). A softly greying nation: Law, Ageing and Policy in Canada. J. Int'l Aging L. \& Pol'y, 2, 1.

Tam, S., \& Neysmith, S. (2006). Disrespect and isolation: Elder abuse in Chinese communities. Canadian Journal on Aging, 25, 141-151. http://doi.org/10.1353/cja.2006.0043

Tyyskä, V., Dinshaw, F. M., Redmond, C., \& Gomes, F. (2012). "Where we have come and are now trapped":and are Views of victims and service providers on abuse of older adults in Tamil and Punjabi Families. Canadian Ethnic Studies, 44(3), 59-77.

Vedung, E. (1998). Policy instruments: Typologies and theories. In M.L. Bemelmans-Videc, C. Ray, and E. Rist (Eds.) Carrots, sticks \& sermons: Policy instruments and their evaluation, New Brunswick, N.J.: Transaction Publishers. Chapter 1 (pp. 21-58).

Walsh, C. A., Olson, J. L., Ploeg, J., Lohfeld, L., \& Macmillan, H. L. (2011). Elder abuse and oppression: Voices of marginalized elders. Journal of Elder Abuse \& Neglect, 23, 17-42. http://doi.org/10.1080/08946566.2011.534705

Walsh, C. A., Ploeg, J., Lohfeld, L., Horne, J., MacMillan, H., \& Lai, D. (2007). Violence across the lifespan: Interconnections among forms of abuse as described by marginalized Canadian elders and their care-givers. British Journal of Social Work, 37(3), 491-514. http://doi.org/10.1093/bjsw/bcm022

Wiebe, J., Single E., Falkowski-Ham, A., \& Mun, P. (2003). Gambling and gambling among older adults in Ontario. Retrieved February 21, 2012 from http://www.gamblingresearch.org/contentdetail.sz?cid=130

Williams, D. R., \& Mohammed, S. A. (2013). Racism and health, I: Pathways and scientific evidence. American Behavioral Scientist, 57(8), 1152-1173.

Young, I. M., (1990). Five faces of oppression. In Justice and the Politics of Difference, pp. 3965. Princeton University Press. 
Young, I. M., (2000). Five Faces of Oppression. In M. Adams, Readings for Diversity and Social Justice, pp. 35-49. New York: Routledge. 